International Journal of Current Advanced Research

ISSN: O: 2319-6475, ISSN: P: 2319 - 6505, Impact Factor: SJIF: 5.995

Available Online at www.journalijcar.org

Volume 6; Issue 5; May 2017; Page No. 3937-3942

DOI: http://dx.doi.org/10.24327/ijcar.2017.3942.0401

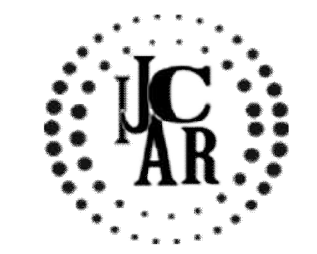

Research Article

\title{
EVALUATING THE PERFORMANCE OF LOGISTICS WITH THE SPECIAL REFERENCE TO TRANSPORT CORPORATION OF INDIA LTD BASED ON CERTAIN SPECIFIC INDICATORS
}

\section{*Arunsankar $\mathbf{N}$ and Santhoshkumar $\mathbf{R}$}

Department of Management Studies, Marian International Institute of Management Peermade

Road Kuttikanam Idukki Dist Kerala, India - 685531

\section{A R T I C L E I N F O}

\section{Article History:}

Received $24^{\text {th }}$ February, 2017

Received in revised form $6^{\text {th }}$ March, 2017

Accepted $14^{\text {th }}$ April, 2017

Published online $28^{\text {th }}$ May, 2017

\section{Key words:}

Logistics, Performance, TCI, Indicators, Field Survey

\begin{abstract}
A B S T R A C T
The study aimed at measuring the Logistics Performance of Transport Corporation of India Ltd in the study area. For this purpose, field survey method and personal interview technique were employed to collect the first- hand information from 500 respondents. The respondents were chosen randomly from the different parts of the study area. The data collected were classified into suitable tables for drawing accurate results, and the data were analyzed by using chi-square test, the study reveals the Performance of the transport corporation of India Ltd., is analyzed on the basis of specific indicators to understand the perception of customers and to measure the competitiveness of transport corporation of India ltd It can help to understand the shortcomings of logistics sectors and find out the ways to improve performance.
\end{abstract}

Copyright $\mathrm{C} 2017$ Arunsankar $\boldsymbol{N}$ and Santhoshkumar $\boldsymbol{R}$. This is an open access article distributed under the Creative Commons Attribution License, which permits unrestricted use, distribution, and reproduction in any medium, provided the original work is properly cited.

\section{INTRODUCTION}

\section{About Logistics Industry}

Logistics, as a business concept, evolved only in the 1950 s. This was mainly due to the increasing complexity of supplying one's business with materials, and shipping out products in an increasingly globalized supply chain. The experts in this field are called Supply Chain Logisticians. Logistics is concerned with getting or transmitting the products and services where they are needed or when they are desired. It is difficult to accomplish any marketing or manufacturing operation without logistical support. Logistics involves in the integration of information, transportation, inventory, warehousing, material handling, and packaging. The operating responsibility of logistics is the geographical repositioning of raw materials, work in process, and finished inventories where required at the lowest cost possible.

\section{Statement of the Problem}

The researcher has identified the problems being faced in the field of logistics the policies which are handled by the top management in Transport Corporation of India Ltd the researcher has provided a frame work for an efficient functioning of logistics operations. The present research seeks to build a knowledge based frame work to topple down all the issues.

\section{*Corresponding author: Arunsankar N}

Department of Management Studies, Marian International Institute pf Management Peermade Road Kuttikanam Idukki Dist Kerala, India particular about Transport corporation of India Ltd.

2. To analyze the performance of Transport corporation of India Ltd.

\section{METHODOLOGY}

The validity of any research depends on the systematic method of collecting the data and analyzing the same in a sequential order. In the present study, an extensive use of both primary and secondary data is made.

\section{Sampling Design}

For collecting primary data, field survey technique was employed in the study area. First-hand information pertaining to the behavior, satisfaction, benefits accrued problems in mobilizing funds and optimum utilization of the funds from various sources under study were collected from five hundred sample respondents.

Transport Corporation of India Ltd has thirty five offices at random in Tamilnadu. The respondents were chosen from all thirty five offices at the rate of fifteen each. The selection of respondents was made in active consultation with finance managers, branch managers of various branch offices of Transport Corporation of India Ltd and the research supervisor, so as to represent all categories such as rural, urban and metro. The respondents were selected on a simple random basis from the managers of Transport Corporation of India Ltd

\section{Tools of Data Collection}

By virtue of a mass of data obtained from research survey, as 
well as data from secondary sources collected and presented in the present report, descriptive and analytical research was considered as most appropriate for the study. The research problems and the questionnaire were all framed accordingly. The suggestions offered in the final chapter of the present research report emerged from the inferences drawn from the study of the sample respondents' information who utilized funds for logistics operations. The researcher used closed ended and open-ended questions in the questionnaire to collect primary data.

\section{Hypothesis Testing}

- $\mathrm{H}_{0}$ : there is no significant difference between expected delivery accuracy and performance of Transport Corporation of India on delivery accuracy.

- $\mathrm{H}_{0}$ : there is no significant difference between expected material handling techniques and performance of Transport Corporation of India on material handling.

- $\mathrm{H}_{0}$ : there is no significant difference between expected goods distribution method and performance of Transport Corporation of India on distribution method.

- $\mathrm{H}_{0}$ : there is no significant difference between expected information system and information system of Transport Corporation of India.

- $\mathrm{H}_{0}$ : there is no significant difference between expected packaging techniques and packaging techniques of Transport Corporation of India.

- $\mathrm{H}_{0}$ : there is no significant difference expected customer friendliness and customer friendliness of Transport Corporation of India.

- $\mathrm{H}_{0}$ : there is no significant difference between expected operating effectiveness and operating effectiveness of Transport Corporation of India.

\section{RESULTS AND DISCUSSION}

\section{Performance of Transport Corporation of India Ltd versus Delivery Accuracy}

Delivery Accuracy is the key factor which enables to measure the performance of Transport Corporation of India Ltd and an attempt has been made to analyze the relationship between the delivery accuracy and the performance of Transport Corporation of India Ltd.

Table 1 Cross Table-Performance of Transport Corporation of India Ltd versus Delivery Accuracy

\begin{tabular}{|c|c|c|c|c|c|c|c|c|}
\hline \multirow[t]{2}{*}{ S. No. } & \multirow{2}{*}{$\begin{array}{l}\text { Delivery } \\
\text { Accuracy }\end{array}$} & \multicolumn{6}{|c|}{$\begin{array}{c}\text { Performance of Transport Corporation of } \\
\text { India Ltd }\end{array}$} & \multirow[t]{2}{*}{ Total } \\
\hline & & Low & $\%$ & Medium & $\%$ & High & $\%$ & \\
\hline & Order & & & & & & & \\
\hline 1 & $\begin{array}{l}\text { Processing } \\
\text { Time }\end{array}$ & 20 & 21.51 & 15 & 12 & 50 & 17.73 & 85 \\
\hline 2 & $\begin{array}{l}\text { Delivery } \\
\text { Accuracy }\end{array}$ & 20 & 21.51 & 20 & 16 & 60 & 21.28 & 100 \\
\hline 3 & $\begin{array}{l}\text { Delivery } \\
\text { Frequency }\end{array}$ & 15 & 16.13 & 30 & 24 & 68 & 24.11 & 113 \\
\hline 4 & $\begin{array}{l}\text { Timely } \\
\text { Delivery }\end{array}$ & 20 & 21.50 & 25 & 20 & 49 & 17.38 & 94 \\
\hline \multirow[t]{2}{*}{5} & $\begin{array}{c}\text { Safety } \\
\text { Delivery }\end{array}$ & 18 & 19.35 & 35 & 28 & 55 & 19.5 & 108 \\
\hline & Total & 93 & 100 & 125 & 100 & 282 & 100 & 500 \\
\hline
\end{tabular}

classified based on the delivery accuracy viz., Order Processing Time, Delivery Consistency, Delivery frequency, Timely Delivery and Safety Delivery. With a view to find the degree of association between the delivery accuracy and the performance of Transport Corporation of India Ltd, a two way table was prepared and is depicted in the following Table 1

The cross Table 4, displays the following respondents feel that frequency of delivery is necessary to measure the performance of Transport Corporation of India Ltd. The order of preference extends to safety, consistency and timeliness. This is general as the people would not consider the order processing time, and also the logistics delivery. At a glance, one can observe the performance of Transport Corporation of India Ltd is at high level and this may be based on the delivery characteristics. Verification of this is supported by the Chi-square test that is displayed in the subsequent Table 1 the underlined hypothesis taken for the Performance of Transport Corporation of India Ltd versus Delivery Accuracy.

Table 1 Chi-Square Statistics

\begin{tabular}{cccc}
\hline & 2value & $\begin{array}{c}\text { Critical } \\
\text { Value }\end{array}$ & $\begin{array}{c}\text { Degrees of } \\
\text { Freedom }\end{array}$ \\
\hline $\begin{array}{c}\text { Performance of Transport } \\
\text { Corporation of India Ltd and } \\
\text { Delivery Accuracy }\end{array}$ & 10.42 & 15.50 & 8 \\
\hline
\end{tabular}

Analysis of Delivery accuracy and performance of Transport Corporation of India Ltd shows that the underlined variables are independent of each other. Statistically, as the test statistic value is lesser than the critical value, the underlined hypothesis is accepted. This means that, Performance of Transport Corporation of India Ltd is high as revealed by the cross table irrespective of various characteristics assumed.

\section{Material handling and Performance of Transport Corporation of India Ltd}

Performance of logistics could be measured by the way how logistics is handled during the course of delivery. Customers feel that their products have to be handled gently with at most care. On the other hand this may not be possible as the logistics to be transported becomes larger and larger. This is where performance is justified. Gentle handling of material differs with respect to product nature, Volume of Material (Logistics), Speed of handle etc,. To ascertain the variation on these factors with performance, association measure of Chisquare test is employed. Cross Table 2, outlines the relationship in most general way.

Table 2 Cross Table-Performance of Transport corporation of India Ltd versus Material Handling

\begin{tabular}{|c|c|c|c|c|c|c|c|c|}
\hline \multirow[t]{2}{*}{ S. No. } & \multirow[t]{2}{*}{ Material Handling } & \multicolumn{6}{|c|}{$\begin{array}{c}\text { Performance Of Transport Corporation } \\
\text { of India Ltd }\end{array}$} & \multirow[t]{2}{*}{ Total } \\
\hline & & Low & $\%$ & Medium & $\%$ & High & $\%$ & \\
\hline 1 & $\begin{array}{l}\text { Volumes to be } \\
\text { handled }\end{array}$ & 55 & 33.95 & 35 & 25.93 & 69 & 33.99 & 159 \\
\hline 2 & Speed in handling & 15 & 026 & 25 & 18.52 & 30 & & 70 \\
\hline 3 & Productivity & 30 & 18.52 & 25 & 18.52 & 26 & 12.81 & 81 \\
\hline 4 & $\begin{array}{c}\text { Product } \\
\text { characteristics }\end{array}$ & 22 & 13.58 & 20 & 14.81 & 23 & 11.33 & 65 \\
\hline 5 & $\begin{array}{l}\text { Nature of the Product } \\
\text { Total }\end{array}$ & $\begin{array}{c}40 \\
162\end{array}$ & $\begin{array}{c}24.69 \\
100\end{array}$ & $\begin{array}{c}30 \\
135\end{array}$ & $\begin{array}{c}22.22 \\
100\end{array}$ & $\begin{array}{c}55 \\
203\end{array}$ & $\begin{array}{c}27.09 \\
100\end{array}$ & $\begin{array}{l}125 \\
500\end{array}$ \\
\hline
\end{tabular}

The cross Table 2 highlights the preference of respondents towards material handling. Customers of logistics desire to have highest priority on Volume of products to be handled. This is most obvious which happens in general cases like purchases. The next character that follows the volume of material is the type of product to be transported. Generally, 
customers prefer to send their product with at most care with the type of product. This is mostly appropriate for the glass materials, electronic goods, perishable products etc,. To have connection with performance and the material handling general associative measure of categorical variables is applied. The result is shown in the Table 3 The Hypothesis undertaken is "Performance of Transport Corporation of India Ltd is not related with Material Handling".

Table 3 Chi-Square Statistics

\begin{tabular}{lccc}
\hline & $\chi^{2}$ value & Critical Value & $\begin{array}{c}\text { Degrees } \\
\text { of } \\
\text { Freedom }\end{array}$ \\
\hline $\begin{array}{l}\text { Performance of Transport } \\
\text { Corporation of India Ltd } \\
\text { and Material Handling }\end{array}$ & 10.71 & 15.50 & 8 \\
\hline
\end{tabular}

The categorical associative measure has shown that the underlined variables are independent at each other. This is because of the result revealed by Chi-square test; likelihood value of test is more than the test statistic value. The researcher had the thought of "Performance of Transport Corporation of India Ltd may be measured in the light of Material Handling". But the statistical procedure has disproved that, the performance is not based on material handling procedure, normally its performance is well.

\section{Distribution and the performance of Transport Corporation of India Ltd}

Distribution shows that how the products are effectively distributed to the clients. Hence, an attempt is made to analyze the relationship between the distribution and the performance of Transport Corporation of India Ltd. For the purpose of the study, the distribution was studied based on five classifications viz., Delivery Time, Lot Size, Packaging, Transportation mode, and Customer Service Norms. With a view to find the degree of association between the distribution and the performance of Transport Corporation of India Ltd, a two way table was prepared and is depicted in the following Table 4.

Table 4 Cross Table -Performance of Transport Corporation of India Ltd versus Distribution

\begin{tabular}{ccccccccc}
\hline \multirow{2}{*}{ S. No. } & Distribution & \multicolumn{7}{c}{ Performance of Transport Corporation of } \\
& & \multicolumn{7}{c}{ India Ltd } \\
\cline { 3 - 8 } & Low & \% & Medium & \% & High & \% & \\
\hline 1 & Delivery Time & 28 & 27.72 & 25 & 25.77 & 82 & 27.15 & 135 \\
2 & Lot Size & 25 & 24.75 & 20 & 20.62 & 45 & 14.9 & 90 \\
3 & Packaging & 15 & 14.85 & 25 & 25.77 & 55 & 18.21 & 95 \\
4 & $\begin{array}{c}\text { Transportation } \\
\text { mode }\end{array}$ & 20 & 19.8 & 15 & 15.46 & 70 & 23.18 & 105 \\
& $\begin{array}{c}\text { Customer } \\
5\end{array}$ & 13 & 12.87 & 12 & 12.37 & 50 & 16.56 & 75 \\
& $\begin{array}{c}\text { Service Norms } \\
\text { Total }\end{array}$ & 101 & 99.99 & 97 & 99.99 & 302 & 100 & 500 \\
\hline
\end{tabular}

The cross Table 5 highlights the preference of respondents towards distribution. Customers of logistics desire to have highest priority on Delivery Time. This is the most common fact that a customer will depends on timely delivery. To have connection with performance and the distribution, general associative measure of categorical variables is applied. The result is shown in the Table 6 The Hypothesis undertaken is "Performance of Transport Corporation of India Ltd is not related with Distribution".
Table 6 Chi-Square Statistics

\begin{tabular}{cccc}
\hline & $\chi^{2}$ value & $\begin{array}{c}\text { Critical } \\
\text { Value }\end{array}$ & $\begin{array}{c}\text { Degrees } \\
\text { of } \\
\text { Freedom }\end{array}$ \\
\hline $\begin{array}{c}\text { Performance of Transport } \\
\text { Corporation of India Ltd } \\
\text { and Distribution }\end{array}$ & 11.38 & 15.70 & 8 \\
\hline
\end{tabular}

The categorical associative measure has shown that the underlined variables are independent of each other. This is because of the result revealed by Chi-square test; likelihood value of test is more than the test statistic value. The researcher had the thought of "Performance of Transport Corporation of India Ltd may be measured in the light of Distribution". But the statistical procedure has disproved that, the performance is not based on distribution, normally its performance is well.

\section{Information System and the Performance of Transport Corporation of India Ltd}

Information System helps to transfer the flow of information between the members in the Transport Corporation of India Ltd in order to have an effective control over on its operation. An attempt has been made to analyze the relationship between information system and performance of Transport Corporation of India Ltd For this purpose the respondents have been classified based on information system viz., reliable, easy access, flexibility, interactive and timeliness.

Table 7 Cross Table-Performance of Transport Corporation of India Ltd versus Information system

\begin{tabular}{ccccccccc}
\hline \multirow{2}{*}{ S. No. } & \multirow{2}{*}{$\begin{array}{c}\text { Information } \\
\text { System }\end{array}$} & \multicolumn{6}{c}{ Performance of Transport Corporation OF } \\
\cline { 3 - 8 } & & Low & \% & Medium Ltd & \% & High & \% & \\
\hline 1 & Reliable & 20 & 22.22 & 30 & 20.69 & 50 & 18.87 & 100 \\
2 & Easy Access & 15 & 16.67 & 20 & 13.79 & 80 & 30.19 & 115 \\
3 & Flexibility & 28 & 31.11 & 35 & 24.14 & 35 & 13.21 & 98 \\
4 & Interactive & 15 & 16.67 & 25 & 17.24 & 55 & 20.75 & 95 \\
5 & Timeliness & 12 & 13.33 & 35 & 24.14 & 45 & 16.98 & 92 \\
& Total & 90 & 100 & 145 & 100 & 265 & 100 & 500 \\
\hline
\end{tabular}

The cross lable 7 highlights the preference of respondents towards information system. In this, the customers of logistics desire to have highest priority on Easy access category. To have connection with performance and the information system, general associative measure of categorical variables is applied. The result is shown in the Table 8 The Hypothesis undertaken is "Performance of Transport Corporation of India Ltd is related with information system".

Table 8 Chi-Square Statistics

\begin{tabular}{cccc}
\hline & $\chi^{2}$ value & $\begin{array}{c}\text { Critical } \\
\text { Value }\end{array}$ & $\begin{array}{c}\text { Degree of } \\
\text { Freedom }\end{array}$ \\
\hline $\begin{array}{c}\text { Performance of } \\
\text { Transport Corporation } \\
\text { of India Ltd Versus } \\
\text { information system }\end{array}$ & 31.54 & 15.70 & 8 \\
\hline
\end{tabular}

The categorical associative measure has shown that the underlined variables are dependent on each other. This is because of the result revealed by Chi-square test; likelihood value of test is less than the test statistic value. The researcher had the thought of "Performance of Transport Corporation of India Ltd may not be measured in the light of information".

\section{Packaging and the performance of Transport Corporation of India Ltd}

Packaging plays an important role in transportation and distribution of logistics management. Customized packaging 
always ensures the safety of goods. An attempt is made to analyze the relationship between packaging and the performance of Transport Corporation of India Ltd For this purpose, the respondents' feedback have been collected and classified into Physical Dimensions, Reusability, Waste disposal, Design and Handling.

Table 9 Cross Table -Performance of Transport Corporation of India Ltd versus Packaging

\begin{tabular}{|c|c|c|c|c|c|c|c|c|}
\hline \multirow{2}{*}{ S. No. } & \multirow{2}{*}{ Packaging } & \multicolumn{6}{|c|}{$\begin{array}{c}\text { Performance of Transport Corporation } \\
\text { of India Ltd }\end{array}$} & \multirow[t]{2}{*}{ Total } \\
\hline & & Low & $\%$ & Medium & $\%$ & High & $\%$ & \\
\hline 1 & $\begin{array}{c}\text { Physical } \\
\text { Dimensions }\end{array}$ & 15 & 15 & 25 & 16.67 & 35 & 14 & 75 \\
\hline 2 & Reusability & 20 & 20 & 30 & 20 & 40 & 16 & 90 \\
\hline 3 & $\begin{array}{l}\text { Waste } \\
\text { disposal }\end{array}$ & 25 & 25 & 25 & 16.67 & 50 & 20 & 100 \\
\hline 4 & Design & 15 & 15 & 35 & 23.33 & 60 & 24 & 110 \\
\hline 5 & Handling & 25 & 25 & 35 & 23.33 & 65 & 26 & 125 \\
\hline & Total & 100 & 100 & 150 & 100 & 250 & 100 & 500 \\
\hline
\end{tabular}

The cross Table 9 exhibits that, most of the respondents feel handling packages is a necessary tool for measuring the performance of Transport Corporation of India Ltd At a glance, one can observe that the performance of Transport Corporation of India Ltd is at high level and this may be based on the handling of packages with care. Verification of this is supported by the Chi-square test that is displayed in the subsequent Table 10 The underlined hypothesis taken for the same is that "Performance of Transport Corporation of India Ltd is independent of Packaging".

Table 10 Chi-Square Statistics

\begin{tabular}{cccc}
\hline & $\chi^{2}$ Value & $\begin{array}{c}\text { Critical } \\
\text { Value }\end{array}$ & $\begin{array}{c}\text { Degree of } \\
\text { Freedom }\end{array}$ \\
\hline $\begin{array}{c}\text { Performance of Transport } \\
\text { Corporation of India Ltd } \\
\text { and Packaging }\end{array}$ & 6.71 & 15.70 & 8 \\
\hline
\end{tabular}

The categorical associative measure has shown that the underlined variables are independent of each other. This is because of the result revealed by Chi-square test; likelihood value of test is less than the test statistic value. The researcher had the thought of "Performance of Transport Corporation of India Ltd may be measured in the light of Packaging".

\section{Customer Friendliness and Performance of Transport Corporation of India Ltd}

Customer Friendliness is an important factor that has an effective control on its operation by way of providing flexible service to the customers. An attempt has been made to study the relationship between the Customer Friendliness and performance of Transport Corporation of India Ltd For this purpose the respondents' feedback have been collected and classified according to information flow, dependency, timely work, communication and relationship.

Table 11 Cross Table - Performance of Transport Corporation of India Ltd versus Customer Friendliness

\begin{tabular}{ccccccccc}
\hline \multirow{2}{*}{ S. No. } & $\begin{array}{c}\text { Customer } \\
\text { Friendliness }\end{array}$ & \multicolumn{5}{c}{$\begin{array}{c}\text { Performance of Transport Corporation } \\
\text { of India Ltd }\end{array}$} \\
\cline { 3 - 8 } & Low & $\mathbf{\%}$ & Medium & \% & High & \% & \\
\hline \multirow{2}{*}{1} & Information & 20 & 23.53 & 30 & 20 & 45 & 16.98 & 95 \\
& Flow & & & & & & & \\
2 & Dependency & 10 & 11.76 & 35 & 23.33 & 40 & 15.09 & 85 \\
3 & Timely Work & 25 & 29.42 & 30 & 20 & 60 & 22.64 & 115 \\
4 & Communication & 20 & 23.53 & 20 & 13.34 & 55 & 20.75 & 95 \\
5 & Relationship & 10 & 11.76 & 35 & 23.33 & 65 & 24.54 & 110 \\
& Total & 85 & 100 & 150 & 100 & 265 & 100 & 500 \\
\hline
\end{tabular}

and performance of Transport corporation of India Ltd.

The cross Table 1.6 highlights that the maximum percentage of high level of satisfied respondents with the relationship extended by Transport Corporation of India Ltd among respondents, who have availed the service of Transport Corporation of India Ltd To have connection with performance and the customer friendliness, general associative measure of categorical variables is applied. The result is shown in the Table 1.6.1. The Hypothesis undertaken is "Performance of Transport Corporation of India Ltd is related with customer friendliness".

Table 12 Chi-Square Statistics

\begin{tabular}{cccc}
\hline & $\chi^{2}$ Value & $\begin{array}{c}\text { Critical } \\
\text { Value }\end{array}$ & $\begin{array}{c}\text { Degree of } \\
\text { Freedom }\end{array}$ \\
\hline $\begin{array}{c}\text { Performance of Transport } \\
\text { Corporation of India Ltd and } \\
\text { Customer Friendliness }\end{array}$ & 18 & 15.70 & 8 \\
\hline
\end{tabular}

It is inferred from the above table that, there is a close relationship between the performance of Transport Corporation of India Ltd and Customer friendliness perceived by the respondents.

\section{Operating Effectiveness and Performance of Transport Corporation of India Ltd}

Operating Effectiveness is a key element for the logistics service providers in terms of ensuring the quality of operations to their customers. An effort has been made to study the relationship between the operating effectiveness and performance of Transport Corporation of India Ltd. For this purpose the respondents' feedback have been collected and classified according to the quality of operations, flexibility, speed of operation, capacity utilization and total productivity. The below cross table exhibits the operating effectiveness and performance of Transport Corporation of India Ltd.

Table 13 Cross Table - Performance of Transport Corporation of India Ltd versus Operating Effectiveness

\begin{tabular}{|c|c|c|c|c|c|c|c|c|}
\hline \multirow{2}{*}{ S. No. } & \multirow{2}{*}{$\begin{array}{c}\text { Operating } \\
\text { effectiveness }\end{array}$} & \multicolumn{6}{|c|}{$\begin{array}{c}\text { Performance of Transport Corporation of } \\
\text { India Ltd } \\
\end{array}$} & \multirow{2}{*}{ Total } \\
\hline & & Low & $\%$ & Medium & $\%$ & High & $\%$ & \\
\hline 1 & $\begin{array}{l}\text { Quality of } \\
\text { Operations }\end{array}$ & 40 & 28.17 & 28 & 20 & 45 & 20.64 & 113 \\
\hline 2 & Flexibility & 20 & 14.08 & 30 & 21.42 & 33 & 15.14 & 83 \\
\hline 3 & $\begin{array}{l}\text { Speed of } \\
\text { operation }\end{array}$ & 35 & 24.65 & 35 & 25 & 55 & 25.23 & 125 \\
\hline 4 & $\begin{array}{l}\text { Capacity } \\
\text { utilization }\end{array}$ & 25 & 17.61 & 27 & 19.29 & 50 & 22.93 & 102 \\
\hline \multirow[t]{2}{*}{5} & $\begin{array}{c}\text { Total } \\
\text { Productivity }\end{array}$ & 22 & 15.49 & 20 & 14.29 & 35 & 16.06 & 77 \\
\hline & Total & 142 & 100 & 140 & 100 & 218 & 100 & 500 \\
\hline
\end{tabular}

The cross table 13 given above displays, the response of customers across Performance of Transport Corporation of India Ltd and the operational service given to the customers. It is noted that, customers who come for service expects the service to be completed in a fast manner. They may have some sort of characteristics in their mind regarding the service. But the major phenomenon that determines performance is fast service. Followed by the fast service the next factor is quality service. This is supported by the highest level of $25 \%$ of respondents. The next highest level of $22.5 \%$ of respondents prefer to have Quality service. To authenticate the above statement, Chi-square analysis is carried out. 
Table 14 Chi-Square Statistics

\begin{tabular}{cccc}
\hline & $\begin{array}{c}\chi^{2} \\
\text { Value }\end{array}$ & $\begin{array}{c}\text { Critical } \\
\text { Value }\end{array}$ & $\begin{array}{c}\text { Degree of } \\
\text { Freedom }\end{array}$ \\
\hline $\begin{array}{c}\text { Performance of Transport } \\
\text { Corporation of India Ltd and } \\
\text { Operating Effectiveness }\end{array}$ & 7.03 & 15.7 & 8 \\
\hline
\end{tabular}

It could be noted from Table 14 that the calculated chi-square value is lesser than the critical value. This leads to a conclusion that there is no relationship between performance of Transport Corporation of India Ltd and Operating effectiveness. Whether the operating process is different or not, the customers get satisfied with the available service which is provided by Transport Corporation of India Ltd .

\section{Findings of the Study}

The following are the major findings arrived from the analysis: the employees level of happiness and satisfaction which in turn reflects their services to the customers and their rapport, the analysis brings to light the following findings on financial performance.

- The overall study reveals that Transport Corporation of India Ltd is the market leader in the logistic industry. On the other hand,

- It is identified from the analysis that a good majority of the respondents felt that the service provided by Transport Corporation of India Ltd is satisfactory.

- The performance of Transport Corporation of India Ltd is the best in the way how materials are handled during the logistics by Transport Corporation of India Ltd.

- The information system used in Transport Corporation of India Ltd has the impact on performance of Transport Corporation of India Ltd.

- The performance of the Transport Corporation of India Ltd is measured based on the relationship it had when the customers approached Transport Corporation of India Ltd for service.

- The performance of Transport Corporation of India Ltd is not measured based on the manner by which the customers get packed.

- The performance of Transport Corporation of India Ltd is satisfactory which is not based on effective operation which is followed in Transport Corporation of India Ltd while delivering the service to the customer.

- The researcher has identified that there are few factors which are highly influencing the top management while taking financial decisions in terms of utilization of the mobilized funds for its logistics operation.

\section{Suggestions of THE Study}

- A good customer relationship is more important to enhance the business performance, especially in service oriented organizations. The transport corporations of India have to establish a good customer management with the present and prospective customers.

- On-line communication about new services offered by the transport corporation of India ltd can be given to the existing customers from time to time.
- Conducting regular training programs for the staff of Transport Corporation of India ltd may help to deliver better quality of services to the customers and also for its survival.

- Transport Corporation of India Ltd have to inspire the customers by its service which will initiate the existing customer to introduce or recommend new customers.

- Transport Corporation of India Ltd need to be competent in modern technology for its survival.

- The good communication skills, logistics operations skills, understanding the new technology and the ability of logistics managers to plan and forecast for the logistics management are highly regarded as desired skills of future logistics managers.

- Based on the research work, the integrated model has been developed for the better utilization of the mobilized funds for the logistics business.

- The government should initiate and implement customized policy, uniform tax to the logistic service providers for the effective operation.

- The reusable or disposable materials should be used with the packing of goods in order to save the environment.

- The customer friendliness needs to be enhanced with their operation systems in order to improve the efficiency of Transport Corporation of India Ltd while delivering the good to the customers.

\section{CONCLUSION}

The performance analysis shows that the Transport Corporation India ltd is the market leader and it has performed well than any other logistics service providers. On the other hand, most logistics service providers offers almost similar services and the customers have little to choose by way of difference in the effective terms of a service. It is in such a situation that good marketing back-up, with service orientation, is bound to become very useful and attractive.

However, a lot has been changing with the government finally realizing the importance of infrastructure and demonstrating a strong commitment towards providing the same along with creating conducive regulations. Regulations around rationalization of tax structures, proposed introduction of GST and prevention of overloading are creating a favorable environment, in which the sector can flourish. Initiatives taken by the government and innovations by industry players are helping them in leveraging the economies of scale and to provide integrated logistics solutions which are cost effective. At the same time, emphasis should be given for the integration of IT enabled technology in the sector. With latest technology, logistics service providers will no longer be restricted to the geographical boundaries but can expand their business to any location.

\section{References}

1. Bo Yuan and Chuanxu Wang, "Research on the Third Part Logistics Company's Financing Pricing under Conditions of Permissible Delay in Payments for Exponentially Deteriorating roducts", IEEE,pp. 861-864, 2010.

2. Bolin LIU and Shaochuan FU, "Efficiency Measurement of Logistics Public Companies Basing on 
the Modified DEA Model”, IEEE, pp.601-605, 2009.

3. Carlos Sanchís-Pedregosa, José A. D. M achuca and María del Mar González-Zamora, "Logistics Outsourcing: Performance Models and Financial and Operational Indicators", IEEE, pp-96-101, 2011.

4. Celik Parkan and Rameshwar Dubey, "Recent Developments in the practice of supply chain Management and Logistics in India Reports", Portuguese Journal of Management Studies, Vol. XIV, No. 1, 2009.

5. Chen Lihong and Peng Fangchun, "Study on Small and Medium-sized Enterprise Supply Chain Financing", IEEE, 2011.

6. Chen Shen, Li-rning Zhao and Yue, L. "The research on the constitution of Financial Logistics Management System", IEEE, pp.1448-1452, 2010.

7. Chen, Xiang-Feng and Xie Xiaoyan, "The value of integrated logistics and finance services of third party logistics firms", International Journal of Services Operations and Informatics, Vol. 4, No. 4, pp. 333351, 2009.

8. Ding and Xiang, “The Listed Company's Financial Evaluation Based on PCA-Logistic Regression Model", IEEE, pp.168-171, 2010.

9. Duan and Weichang, "A Rapid Decision-Making Model in Supply Chain Finance Emergency Based on GDSS", IEEE, pp-539-543, 2009.

10. Duan Weichang, "Benefits Distribution Model of High-risk Projects Based on Deferral Options for Supply Chain Finance", IEEE, pp.84-87, 2010.

11. Haipeng Wang, "Study on Supply Chain Finance in Ebusiness Circumstances”, IEEE, pp-507-509, 2010.

12. He Juan, Chen Xiangfeng and Li Ming, "Analysis of Logistics Financing Risk Based on the Structural Equation Modeling”, IEEE, 2009.

13. $\mathrm{Hu}$ Qin, "Risk Analysis and Countermeasures Concerning of SMEs in China under Logistical Finance", IEEE, pp. 326-329, 2011.

14. Indian Logistics Industry", Scope Marketing \& Information Solutions, 2010.

15. Jian $\mathrm{Xu}$ and Xiqin Han, "Analysis on Linkage Mechanism between Manufacturing and Logistics Industry”, IEEE, pp. 3200-3203, 2010.
16. Jiancai Yang, "The Empirical Analysis of Automobile Logistics Based on The Principle Component Analysis", IEEE, 2011.

17. Li Wenjing and Xia Chunyu, "The Impact of Logistics Mode on Retailer's Logistics Performance Measurement System”, IEEE, 2010.

18. Li, Yixue' Wang, Shouyang' Feng, Gengzhong and Lai, Kin Keung' "Comparative analysis of risk control in logistics and supply chain finance under different pledge fashions", International Journal of Revenue Management, Vol.5, No. 2-3, pp. 121-144, 2011.

19. Lijuan and Xuyu, "Optimal-decision Research on Ordering Financing Based on Supply Chain Finance”, IEEE, 2010.

20. Liu Xiang, "A multiple criteria decision-making method for enterprise supply chain finance cooperative systems", IEEE, pp.120-125, 2009.

21. Liu Xiang, "Context-aware data mining methodology for supply chain finance cooperative systems", IEEE, pp.301-306, 2009.

22. Lu Zheng-hua, Dai Qi-li and Chen Xiu-de, "An Analysis on Logistics Finance Based on Third Party Logistics and the Financing Model”, IEEE, 2009.

23. Lu Zheng-hua, Dai Qi-li and Chen Xiu-de, "An Analysis on Logistics Finance Based on Third Party Logistics and the Financing Model", 2009.

24. Lu Zheng-hua, Dai Qi-li and Chen Xiu-de, "An Analysis on Logistics Finance Based on Third Party Logistics and the Financing Model”, IEEE, 2009.

25. Luo Jianfeng and Ma Tianshan, "An Comprehensive Rating Model of Manufacturing Enterprise's Credit Risk Based on Logistics Finance", IEEE, V15-290293, 2010.

26. Luo Jianfeng, Zhou Lingyun and Ma Tianshan, "A Comprehensive Evaluation Method of Logistics Company's Credit Risk Based on Logistics Finance”, IEEE , pp. 299-302, 2010.

27. Miao He, Changrui Ren, Qinhua Wang and Jin Dong, "An Innovative Stochastic Dynamic Model to Threestage Supply Chain Finance”, IEEE, pp.13-318, 2011.

28. Miao He, Changrui Ren, Qinhua Wang and Jin Dong, "An Innovative Stochastic Dynamic Model to Threestage Supply Chain Finance”, IEEE, pp.313-318, 2011.

\section{How to cite this article:}

Arunsankar N and Santhoshkumar R (2017) 'Evaluating The Performance Of Logistics With The Special Reference To Transport Corporation Of India Ltd Based On Certain Specific Indicators', International Journal of Current Advanced Research, 06(05), pp. 3937-3942.DOI: http://dx.doi.org/10.24327/ijcar.2017.3942.0401 